\title{
Structural equation modelling of building quality constructs as a predictor of satisfaction in subsidised low-income housing
}

\author{
Clinton Aigbavboa \\ Wellington Thwala
}

Clinton Aigbavboa, University of Johannesburg, Faculty of Engineering and the Built Environment, Department of Construction Management \& Quantity Surveying, South Africa (caigbavboa@uj.ac.za)

Wellington Thwala, University of Johannesburg, Faculty of Engineering and the Built Environment, Department of Construction Management \& Quantity Surveying, South Africa (didibhukut@uj.ac.za)

\begin{abstract}
Residents' satisfaction with the building quality and housing condition features has received an increasing recognition as a significant factor which influences the occupants' satisfaction with their housing units. This paper reports the use of Structural Equation Modelling technique to test the influence of building quality features as a predictor of residents' satisfaction. The study was conducted amongst South Africa housing practitioners' and the low-income housing occupants'. Data used in the study were obtained from a Delphi and field questionnaire study. Primary data were collected by a face-to-face administered questionnaire survey conducted among 751 low-income housing residents' in three metropolitan and one district municipality in the Gauteng Province of South Africa. Data gathered via the questionnaire survey were analysed using structural equation modelling (SEM) which was used to assess the factorial structure of the constructs. Using Structural Equation Modelling software - EQS version 6.2, the factorial structure, reliability and validity of building quality features indicator variables were investigated. The statistical results support the research hypothesised positive relationship that building quality feature has a direct influence in predicting residents' satisfaction with their houses. Also, the influence of building quality feature on residents' satisfaction was statistically significant. Further SEM analysis revealed that the Rho and the Cronbach's alpha coefficients of internal consistency were over 0.70 criterions for acceptability, and the constructs shows a good mode fit to the sample data. The Zstatistics analysis also revealed that the constructs have direct influence in determining low-income residents' satisfaction with their houses. The result advocates a practical consideration of these construct in future development of subsidised low-income housing in South Africa.
\end{abstract}

Keywords: residential satisfaction, building quality features, Structural Equation Modelling, South Africa

\section{Introduction}

Housing satisfaction describes an 'end-state', where an individual or household is satisfied with the residential status they have attained (Weidemann \& Anderson, 1982). It is not one constant experience or state; it is an outcome, perceived by an individual or household, that their current housing status meets their needs and aspirations (Potter, Chicoine, Speicher, \& Kathryn, 2001). It is based upon the perception of the housing occupants' on the features within and around the housing environment. This process, aligns with the theories of residential satisfaction which are based on the notion that residential satisfaction measures the difference between households' actual and desired housing and neighbourhood situations (Galster \& Hesser, 1981). Hence, satisfaction with their housing conditions indicates the absence of complaints as their needs meet their aspirations.

The formation of residential satisfaction is not simply based upon freedom from dissatisfaction; it is more complex (Lu, 1999). It is a differently composed construct; the 
causes of dissatisfaction are more likely to be a universal source of discontent for everyone (Hourihan, 1984), whilst the sources of satisfaction are much more diverse. This is the case with the beneficiaries of the South Africa low-income subsidy schemes, where there is a general dissatisfaction with the initially provided 30 square meters housing unit situated in a 250 square meters of land; though, this have since been increased to a minimum of 40 square meters based on the revision of policies governing low-income housing in South Africa. This adjustment, was driven by a political need to deliver acceptable 40 square meters houses, was not rooted in a deeper understanding of the consequences of the service levels/location/topstructure trade-off on beneficiaries. Rather, it was an irritable move related to the historic rejection of the notion of 'incrementalism' - the gradual consolidation of a starter house over time by the end-user - and may again, in fact, have further contributed to the spatial marginalization of the poor (Tomlinson, 1999; Charlton and Kihato, 2006). Also, the national budget allocations to housing are wholly inadequate to deal with the enormous backlog, and desperately needs to be increased and a as a result of the government's decision to target "breadth, not depth" (Tomlinson, 1998). One of the main reasons of dissatisfaction was that the area estimation of the constructed housing units never took into consideration the housing life cycle of the beneficiaries and other dynamics that are relevant to the beneficiaries' optimal usage of the housing units such as the improvement of the building quality features.

A building's success depends not only on how effectively the building provides the setting for activities of daily living but also on the perceptions of its residents with regards to the provided features necessary to meet their daily usage (Turner, 1972; 1976). For instance, Francescato, Weidemann, and Anderson (1987) suggest that residence satisfaction with any residential dwelling depends on three elements, which are: the design of the house, (i.e. the dwelling space organisation, layout and facilities provided); the management practices; and the surrounding social aspects. Varady and Carrozza (2000) and Salleh et al. (2011), acknowledge that residential satisfaction encompasses four distinct types of satisfaction, which include: satisfaction with the dwelling unit; satisfaction with the services provided, including repair services; satisfaction with the whole package received, as in the case of public housing, where no rent is paid (dwelling and service); and satisfaction with the neighbourhood or area. In this regards, adequate provision of the right building quality features for a new housing project for the low-income (poor) goes a long way to underpin the success or failure of the housing programmes supporting the housing development. Hence, by undertaking building occupants' satisfaction evaluation towards a product or a service; it is believed that improvements could thus be found which will be allocated to the right places and in the right direction (Yiping, 2005). This will thus enhance the efficacy of the production or service provided.

Therefore, the objective for the present research is to present how structural equation modeling technique was used to test the influence of building (housing) quality features as a predictor of residents' satisfaction in subsidised low-income housing in South Africa. The study was conducted amongst South Africa housing practitioners' and the low-income housing occupants'. The article commences by reviewing the literature on housing quality features and a brief background of subsidised housing in South Africa. This is followed by a discussion of the research method used in achieving the research objective; followed by the presentation of the research findings and a concurrent discussion of the results. Finally, the paper draws some conclusions. The present article contributes to the existing literature in three ways. Firstly, it enriches housing literature theoretically. It extends the meaning and dimensions of housing satisfaction through the literature discussed with regards to building (housing) quality features. Secondly, the study has the potential to contribute to the literature practically; uncovering building quality factors that predict housing satisfaction of lowincome occupants. Lastly, the study contributes to the existing literature through the 
methodology adopted for the study which enables the validation of building quality as causative in the prediction of residents' satisfaction. Hence, the results of this study may assist architects, city planners, and housing authorities in designing and constructing better quality, sensitive and livable housing settings with reference to the identified building quality features. This is because of the deliberate urban spatial policy which used the urban planning system as a means to segregate spatial land uses into economic class antagonism. Thus, making the housing environment in South Africa to be very complex, in large part due to the deliberate policy and legislative framework of socio-economic and spatial exclusion and marginalization created during the Apartheid Era (Huchzermeyer, 2003). Hence, this article makes a significant contribution towards understanding residential satisfaction in subsidised low-income housing developments in South Africa. The next section of the article presents some background literature on building quality feature.

\section{Building Quality Features}

According to Altas and Ozsoy (1998), residential satisfaction and quality of housing are two mutually related concepts in housing evaluation studies. In some previous research, satisfaction is referred to as a criterion for evaluating the quality of the residential environment by measuring the effect of perception and assessments of the objective environment upon satisfaction. While Weidemann and Anderson (1985), refers to the outcome of the perception from quality of housing as a predictor of behaviour. Numerous authors have studied the determinants of housing satisfaction and the link between satisfaction and building quality or housing conditions. Research has shown that housing satisfaction is related to; for instance the quality of the floor finishes (external and internal) amongst others (Ukoha \& Beamish, 1997; Aigbavboa \& Thwala, 2010). However, Hintz and Null (1988) states that satisfaction with building quality features varies by social class because people in lower socio-economic groups aspire to amenities that the upper classes tend to take for granted. This according to Kinsey and Kane (1983) is due to different preferences and expectations by each class of people.

Hence, Morris and Winter (1978), defined housing (building) quality, as the perceived desirable characteristics of a dwelling by its users or observers. When there are perceived housing quality deficits, the users determines what housing quality characteristics should be in totality or those undesirable. Residents' satisfaction towards a given housing unit is likewise derived from the satisfaction with the building quality and the housing condition features in the buildings (Ukoha \& Beamish, 1997). Onibokun (1974) classified building condition features as dwelling subsystems to the human habitat that influence the level of housing satisfaction. This position was further supported by McCray and Day (1977) who states that low-income housing construction is rarely developed to reflect the needs and types of families who are going to inhabit the houses, as the building condition / quality elements are seldom considered in the establishment of human habitats. Whereas, the quality of lowincome housing should be a combination of both the user's requirements and the principles that define adequate housing. But because public low-income housing is built for the poor and disadvantaged, with the cost being covered by the government; the choices of design and materials used during construction are only based on an affordable budget; which compromises best practices with regards to adequate housing for the low-income groups. Hence, Kutty (1999) claims that a good building structure with good quality is an important indicator that determines the residents' satisfaction with the building and the value they place on the dwelling.

Similarly, Franescato, Weidemann, Anderson and Chenoweth (1974) conceive satisfaction as a function of different categories of variables: the objective characteristics of the residents, objective characteristics of the housing environments, and the occupants' 
perception and beliefs about the aspects of their housing environment which are the physical environment, the housing management, and the other residents. Marans and Sprecklemeyer's (1981) model of residents' satisfaction recognises the attributes of housing quality features by indicating that objective attributes of a particular house have an influence upon a person's satisfaction through the person's perception and assessments of those environmental attributes. It further states that a person's behavior is influenced by satisfaction - the perception and assessments of the objective environmental attributes, and the objective attributes of the environment itself.

According to Duncan (1971) and Ramdane and Abdullah (2000), three dimensions of housing quality are usually considered with regards to dwellings, which include: internal aspects of a dwelling unit, its external aspects, as well the surrounding area. Furthermore, Elsinga and Hoekstra (2005) inform that the higher quality a dwelling is, the higher the resident's satisfaction with it. Elsinga and Hoekstra further state that housing quality and condition should not be assessed based on one variable only, but from objective and subjective dimensions. This was also supported by the Marans and Sprecklemeyer's (1981) study. Also, Kain \& Quigley (1970) divided housing quality into five critical factors namely: basic housing quality factor; dwelling unit quality factor; surrounding property quality factor; non-residential land use quality factor; and structural average quality factor. According to Kain \& Quigley (1970), basic housing quality factors refer to the index used to measure the surrounding areas and the external physical quality of the unit. While the dwelling unit quality factor is assessed from the structural aspects and internal hygiene of the dwelling unit; surrounding property quality factor is assessed from the general cleanliness of the surrounding area, its ambience and landscaping. The factor of quality for non-residential uses is measured from the effects of industrial and commercial uses in residential areas. These effects are assessed based on the level of discernible noise, air quality and traffic flow in the area. The structural average quality factor is assessed based on the structural quality on the building facade.

Building quality factors that have been found to mostly contribute to residents' satisfaction with their dwelling units include: wall, floor, window, roof, door and painting quality, amongst others (Salleh et al., 2011; Ukoha \& Beamish, 1997). For instance, the materials used for wall construction gives effect to the building temperature. Besides, the quality of windows should provide good ventilation and air circulation in the units, because if the windows are unable to open, it will increase the heat in the unit; hence, residents will be uncomfortable in their houses. However, the housing quality standards set by most governments who embark on state own housing and the decisions made by the appointed advisers and architects compromise good practice for the total well-being of the housing occupants and falls short of the acclaimed standard for adequate housing. It is imperative to know that future generations will live and grow in the homes being built today which will be echoed through tomorrow's society. The development will impact either positively or negatively on the quality of life of the housing residents and in the society at large.

Good building standards and adequate quality of low-income housing units are at the forefront of the housing debate in South Africa. This debate, is driven by a political need to deliver acceptable houses to the poor and previously marginalised through the gradual consolidation of a starter house over time by the end-user thus correcting the spatial marginalization of the poor (Huchzermeyer, 2003). However, despite the government set documented acceptable standards required for contractors and developers; there are still gross inadequacies with the delivered product (Huchzermeyer, 2001). Various NGO's and communities have lodged numerous complaints at the building quality of stated subsidised low-income houses in South Africa (Moolla et al, 2011; Aigbavboa \& Thwala, 2012). Questions have also been raised regarding the sustainability of these communities because of 
the quality or the limited or substandard building quality features in the delivered houses. The building quality features considered for the present study are summarised in Table 1.

Table 1.Building Quality Features Conceptual Variables

$\begin{array}{ll}\begin{array}{l}\text { Building } \\ \text { Features (BQF) }\end{array} & \text { External construction quality (BQF1) } \\ & \text { Internal construction quality (BQF2) } \\ & \text { Water pressure (BQF3) } \\ & \text { Wall quality (BQF4) } \\ & \text { Floor quality (BQF5) } \\ & \text { Window quality (BQF6) } \\ & \text { Door quality (BQF7) } \\ & \text { Internal painting quality (BQF8) } \\ & \text { External painting quality (BQF9) } \\ & \text { Plumbing quality (BQF10) } \\ & \text { The finished quality of sanitary system } \\ & \text { (BQF11) } \\ & \text { Electrical wiring quality (BQF12) } \\ & \text { Electrical fittings quality (BQF13) } \\ & \text { Numbers of electrical sockets (BQF14) } \\ & \text { Level of socket (BQF15) } \\ & \text { Overall unit quality (BQF16) } \\ & \end{array}$

\section{Subsidised Housing in South Africa}

State subsidised housing in South Africa is a form of housing delivery system in which the property and associated infrastructure is financed by the government and transferred to either a group of qualified low-income families, elderly and handicapped individuals with little or no contribution coming from them. However, it has never proved easy to help the poor through housing subsidies, particularly in developing countries (Gilbert, 2004) such as South Africa with numerous social-economic issues and racial divides. Today, very few governments are prepared to offer housing subsidies to the poor unless they are delivered as up-front or as, targeted capital subsidies. Also, the lack of resources has forced most governments into making difficult decisions about the sise and the numbers of subsidies to be offered.

In order to address the housing shortage and the urban and rural housing backlog in the Post-Apartheid South Africa State, the government instituted a number of programmes and mechanism to assist lower income households. Foremost amongst these include the housing subsidy system, as well as other innovative mechanisms to encourage the increase of affordable housing to the poor (Landman \& Napier, 2010). Also dependent on these decisions, has come a series of implementation problems relating to the quality of construction, the location of the new housing solutions, the use of credit and how to allocate subsidies between so many beneficiaries. While there have certainly been positive experiences from the South Africa housing delivery mechanism, there is also a very long list of failures particularly with the process of delivery and the product that was and is still being delivered. Housing delivery for the low income groups in South Africa is reliant on the Housing Subsidy process. The subsidy scheme facilitates the provision of a range of housing types.

Despite the impressive delivery of low-income houses in South Africa, the housing backlog has increased from 1.5-million in 1994 and is currently estimated at between 2.1million and 2.5-million. This, according to the Department of Human Settlement translates 
into approximately 12.5 million people still needing houses in the country. Despite this impressive statistics, the government's 2010 General Household Survey showed that the portion of households still living in shacks has remained steady at about 13 percent since 2002. Also, subsidy housing for homeownership comprise $15.2 \%$ of the total stock in South Africa, with social housing (rental) constitutes $0.5 \%$ and co-operatives $1.6 \%$ (based on the 2001 Census). Though, delivery through social housing has significantly increased since then, but this still constitutes a small percentage of the overall housing supply in the country. Other forms of state provided housing include public housing at a local level. However, Statistics SA (2010) informs that around 18.9 percent of South African households live in state subsidised homes according to its General Household Survey report and another 13 percent are waiting for a state subsidised housing unit. Government subsidised homes, usually includes a stand-alone house of about $30-40 \mathrm{~m}^{2}$ on a $250 \mathrm{~m}^{2}$ plot. Lately, developers and designers have started to experiment with alternative housing types where the units are semidetached and located on smaller sites to accommodate densification.

The critiques of South Africa's subsidised housing policy are many, and varied. Champions of the program proclaim it for the main reason that the apartheid policy was such an utter failure; that it has attempted, and gone some of the way to providing housing for all. The scale of the project is tremendous to some extent regardless of the criticism. For instance, at macro-level, the effects of the program are plain to see - an estimated 13 million people or more, have benefited directly from the program. During a period of worsening poverty and unemployment, enormous urbanization, and high population and household growth- the rate of households living in informal housing has actually increased, especially among the African population. At the same time, however, the national budget allocations to housing are wholly inadequate to deal with the enormous backlog, and desperately needs to be increased (Tomlinson, 1998' Aigbavboa \& Thwala, 2012; 2013). Also, Lipman (1998), in an article entitled 'Apartheid ends, but they're still put in little boxes, little boxes all the same', commented that newly built houses did not differ much in quality and location to the kind of housing built for migrant labourers by the apartheid government in the 1950's and 60's which encapsulate the two main complaints about housing policy in South Africa. The first relates to the quality of the housing, which has been of a very basic, if not insufficient, quality as a result of the government's decision to target "breadth, not depth" (Tomlinson, 1998). Especially in the beginning of the program, the houses were far too small, and were alleged to be worse living environments than even the shacks from which people had moved. While the minimum quality requirements have been implemented ever since, the housing product delivered is still not of a very high standard. The second set of critiques take aim at the policy's planning and the choice of project location which reinforced the spatial logic of apartheid (Huchzermeyer, 2003) by continuing to settle poor communities on the periphery of cities, missing a great opportunity to break down racial segregation and economic marginalization.

\section{Methodology}

The study was conducted using both qualitative and quantitative data collection methods. For the qualitative aspect, a Delphi technique was used while field questionnaire survey was used for the quantitative aspect. The Delphi survey was conducted amongst 15 sustainable human settlement experts drawn from the nine provinces of South Africa. The output from the Delphi techniques assisted to refine the conceptual variables for the building quality features (BQF) as derived from the literature. With regards to the quantitative aspect of the study, a questionnaire survey was conducted among 751 randomly selected low-income housing residents' in three metropolitan and one district municipality in the Gauteng Province of South. The adopted sample sise was due to the kind of data analysis method (Structural 
Equation Modeling) to be used in this study in order to avoid negative results, which will jeopardise the model goodness-of-fit; thus failing to establish the truth with regards to the constructs which predict building quality and resident's satisfaction. A sample sise of 751 was considered from a total of 20658 low-income buildings. This is because the role of sample sise is crucial in SEM analysis (Lucko \& Rojas, 2010). Hence, Kline (2010) suggested that a path model analysis via SEM needs a sample sise of 200 or more. Also, Bagozzi and Yi (2012) proposed that the sample sise for SEM analysis should be above 200 for analysis if covariance structure estimate.

All completed, allocated and occupied subsidised low-income housing units in each housing location area in the identified metropolitan and district municipalities were chosen as the sample frame. The sample frame were the beneficiaries (occupants) of the subsidised lowincome housing that are occupied. To establish the sample frame, a list of the numbers of subsidised low-income houses in the respective population was obtained from the municipalities and confirmation from the Affordable Land \& Housing Data Centre Suburb Profile, which has a comprehensive data, capturing of the number of houses in South Africa (enumerated total number of low-income houses developed in South Africa).

The current study used the probability sampling method, which allows all segments of the low-income population as defined above to be represented in the sample, making sure that a representative sample of low-income housing is selected for this study. Therefore, a simple random and cluster sampling techniques were used, which allows each member of the population to have an equal chance of being selected (Kerlinger \& Lee, 2000) whilst a cluster sampling technique divided the population into an expansive area with each cluster containing an equally heterogeneous mix of individuals. The rationale for selecting this method of sampling is based on the nature and composition of the low-income housing landscape in South Africal- hence cluster random sampling was used to ensure representativeness. The selection of a representative sample for this study was based on the justification by Smith (2004) who informed that random sampling must be used for a study of this nature, hence it was adopted.

The evaluated factors in the study were identified during the course of the literature review and were further validated via the Delphi study. An existing valid survey instrument was not used, but the developed questionnaire was further validated via the SEM output. Data gathered via the questionnaire survey were analysed using structural equation modelling (SEM) software, EQS Version 6.2, which was used to assess the factorial structure of the constructs. The conceptual variables were thereafter tested as a priori using SEM of the questionnaire survey results. The SEM process was therefore undertaken as confirmatory factor analysis (CFA) of the priori model. Due to the limited space in current paper, the Delphi process is not discussed.

\section{Model testing}

Structural equation modelling (SEM) using EQS Version 6.2 (Bentler \& Wu, 1995) was used to test the BQF priori. The construct parameters were estimated using the Maximum Likelihood method. Because psychometric data have a tendency not to be normally distributed; hence, consideration was given to the Mardia coefficient. Meaning, if the Mardia values showed significant deviation from normality, the Satorra-Bentler Scaled statistics (Robust) would be used as these have been found to perform adequately under such conditions (Bentler, 1988). In establishing the score reliability, the construct validity for the variables was conducted to demonstrate the extent to which the constructs hypothetically relate to one another. This is also referred to as the test of, factorial invariance or measurement invariance (MI) or measurement equivalence between indicator variables. Factorial invariance (FI) is a very important requisite in Structural Equation Modeling. It 
attempts to verify that the factors are measuring the same underlying latent construct within the same condition. FI ensures that the attributes must relate to the same set of observations in the same way. The FI for BQF was determined based on examination of the residual covariance matrix from the SEM output result as opposed to the correlation matrix. Covariance matrix establishes the variables that adequately measure the BQF construct which predict residents' satisfaction.

Hereafter, preliminary Confirmatory Factor Analysis (CFA) was performed to measure the building quality variable indicators to identify which items appropriately measures the building quality features. Hence, BQF indicator variables with an unacceptably high residual covariance matrix ( $>2.58$ ) were dropped, meaning that they do not sufficiently measure the building features regardless of their importance in other cultural contexts and past research studies. Residual covariance matrix values greater than 2.58 are considered large (Byrne, 2006; Joreskog \& Sorbom, 1988). Therefore, in order for a variable to be described as wellfitting in measuring a construct like building quality and thus predicting residents' satisfaction, the distribution of residuals covariance matrix should be symmetrical and centered around zero (Byrne, 2006; Joreskog \& Sorbom, 1988). This procedure was adopted as a means to ensure that the indicator variables were measuring the same latent construct.

\section{Results}

\section{Measurement Model for Building quality features}

From a total sample of 751 responses, the number of cases that were analysed was 745 . Six cases were skipped because of missing variables. A detailed examination of the pattern of missing data revealed that the missing data was missing at random (MAR) and not missing completely at random (MCAR). According to McDonald and Ho (2002), the condition that data was missing completely at random is a situation where the presence or absence of the observation is independent of other observed variables and the variable itself. Hence, the robust maximum likelihood estimation solution in EQS was used to address the problem.

Initial assessment of the data revealed that the residual covariance matrix scores for ten indicator variables (BQF1, BQF6 - BQF9, \& BQF12 - BQF16) had high values (3.20 - 4.52). Therefore, they were dropped from further CFA analysis. Thus, only six indicator variables passed the test and were used for the assessment of the BQF measurement model goodnessof-fit. The question of how many factors a construct should have is debatable (Bollen, 1989; Hayduk \& Glaser, 2000). However, some scholars have informed that a minimum of four indicator variables should be used whilst others have recommended five (Bollen, 1989; Byrne, 2006; MacCallum et al., 1996). Further, analysis of the Mardia values showed that the data deviated significantly from normality (Mardia $=27.47$ ), hence the decision was to use the robust maximum likelihood method which assumes multivariate normality.

Table 2: Robust Fit Indexes for Building quality Feature Construct

\begin{tabular}{|c|c|c|c|}
\hline Fit Index & Cut-off value & Estimate & Comment \\
\hline$S-B \chi^{2}$ & & 76.438 & \\
\hline$D f$ & $0 \geq$ & 9 & Acceptable \\
\hline CFI & $\begin{array}{l}0.90 \geq \text { acceptable } \\
0.95 \geq \text { good fit }\end{array}$ & 0.964 & Good fit \\
\hline SRMR & $\begin{array}{l}0.08 \geq \text { acceptable } \\
0.05 \geq \text { good fit }\end{array}$ & 0.039 & Good fit \\
\hline RMSEA & $\begin{array}{l}0.08 \geq \text { acceptable } \\
0.05 \geq \text { good fit }\end{array}$ & 0.100 & Acceptable fit \\
\hline $\begin{array}{l}\text { RMSEA } \\
90 \% \text { CI }\end{array}$ & & 0.080:0.121 & $\begin{array}{l}\begin{array}{l}\text { Slightly out of } \\
\text { range }\end{array} \\
\end{array}$ \\
\hline
\end{tabular}


Examination of the Bentler-Weeks structure representation for the approved construct revealed that the BQF construct has 6 dependent variables, 7 independent variables and 12 free parameters. The number of fixed non-zero parameter was 7 . As shown in Table 2, the sample data on BQF measurement model yielded an $S-B \chi^{2}$ of 76.438 with 9 degrees of freedom. The associated $p$-value was determined to be 0.0000 . In multivariate analysis, when the $p$-value is high, there is less possibility of an association between two variables (McClave, Benson \& Sincich, 2008); while a smaller $p$-value gives a better likelihood of association. The chi-square value advocated that the difference between the sample data and the postulated BQF measurement model was insignificant. From these values, the normed chi-square value was determined to be 8.4931 . The normed chi-square is the procedure of dividing the chisquare by the degrees of freedom. The normed values of up to 3.0 or 5.0 are recommended (Kline, 2005). The ratio of $S-B \chi^{2}$ to the degrees of freedom was higher than the upper limit value of 5.0 suggesting a mediocre fit of the sample data to the construct. However, the chisquare statistics is only indicative of fit and therefore, other goodness-of-fit indexes were reviewed.

The goodness-of-fit indexes are presented in Table 2. The robust Comparative fit index (CFI) of 0.964 was higher than the cut-off value for a good fitting model. A model is said to be a good fit if the CFI is above the cut-off value of 0.95 (Hu \& Bentler, 1999:27; Joreskog \& Sorbom, 1996). The robust root mean square error of approximation (RMSEA) with 90\% confidence interval was found to be 0.100 (lower bound value $=0.080$ and the upper bound value $=0.121)$. This value was slightly below the maximum value of 0.08 for a good fit model. However, this is considered an acceptable mediocre model fit (MacCallum et al., 1996).

In addition, the absolute fit index, Standardised root mean square residual (SRMR) was found to be 0.039 . This value indicated a very good fit because a good fitting model is expected to have an SRMR index lower or equal to 0.05 , whilst an index of 0.08 is sufficient to accept the postulated model. The absolute fit index SRMR accounts for the average discrepancy between the sample and the postulated correlation matrices and therefore, it represents the average value across all standardised residuals and ranges between zero and 1.00 (Byrne, 2006). Evaluation of the SRMR, RMSEA (90\% CI) and the CFI fit indexes indicated an acceptable fit of the measurement model for the building quality feature factors.

\section{Testing the influence of Building quality Features (BQF) on residents' satisfaction}

In order to determine the internal consistency of the composition of the measurement model, the Rho coefficient and Cronbach's (1951) alpha $(\alpha)$ were examined to establish the reliability. Byrne (2006) and Kline (2005) theorise that Cronbach's alpha measures the degree to which responses are consistent across all items within a single measure and if this statistics is low, the content of the items may be so heterogeneous that the total score is not the best possible unit of analysis for the measure. Hence, the acceptance of Cronbach's Alpha to measure internal homogeneity is limited.

Table 3: Reliability and Construct Validity of BQF Model

\begin{tabular}{lllllll}
\hline $\begin{array}{l}\text { Indicator } \\
\text { Variables }\end{array}$ & $\begin{array}{l}\text { Stand. } \\
\text { Coff. }(\boldsymbol{\lambda})\end{array}$ & Z-Stats & $\mathbf{R}^{2}$ & $\begin{array}{l}\text { Total } \\
\text { Variance }\end{array}$ & $\begin{array}{l}\text { Factor } \\
\text { Loading }\end{array}$ & $\begin{array}{l}\text { Sign. 5\% } \\
\text { level }\end{array}$ \\
\hline BQF2 & 0.774 & $* *$ & 0.523 & $60.75 \%$ & 0.769 & Yes \\
BQF3 & 0.441 & 8.551 & 0.450 & $46.87 \%$ & 0.468 & Yes \\
BQF4 & 0.894 & 28.198 & 0.419 & $64.13 \%$ & 0.893 & Yes \\
BQF5 & 0.894 & 28.944 & 0.579 & $64.13 \%$ & 0.897 & Yes \\
BQF10 & 0.813 & 25.657 & 0.145 & $61.92 \%$ & 0.809 & Yes
\end{tabular}




\begin{tabular}{lllllll} 
BQF11 & 0.651 & 18.623 & & $56.56 \%$ & 0.649 & Yes \\
RS1 & 0.797 & $* *$ & 0.635 & $61.45 \%$ & 0.718 & Yes \\
RS3 & 0.510 & 13.527 & 0.260 & $50.50 \%$ & 0.551 & Yes \\
RS5 & 0.391 & 9.122 & 0.153 & $43.88 \%$ & 0.479 & Yes \\
RS7 & 0.617 & 14.956 & 0.381 & $55.24 \%$ & 0.644 & Yes \\
\hline
\end{tabular}

Cronbach's Alpha = 0.885; Rho Coefficient $=0.892$

Notes: Robust Statistical Significance at 5\% level

** SEM Analysis Norm (Kline, 2005) - One variable loading per latent factor is set equal to 1.0 in order to set the metric for that factor. *Parameter estimates are based on standardised solutions

Byrne (2006) argues that the use of the Cronbach's Alpha Coefficient to judge latent variable models especially models with multi-dimensional structure is questionable because it is based on a very restrictive model that requires all factor loading and error variances to be equal. Therefore, in establishing score reliability for the analysis, the Rho Coefficient was relied upon more than the Cronbach's Alpha Coefficient even though it is the most common method used for assessing the reliability for a measurement scale with multi-point items (Hayes, 1998). This is because the Rho coefficient provides a good estimate of internal consistency because the model that was analysed in the current study was a full latent variable mode (Byrne, 2006).

According to Kline (2005), the reliability coefficient should fall between zero and 1.00. Values close to 1.00 are desired. The Rho Coefficient of internal consistency was found to be 0.892. This was above the minimum value of 0.70. Equally, the Cronbach's Alpha was also found to be above the minimum value of 0.70 at 0.885 . Both values showed a high level of internal consistency and therefore reliability (Table 3).

The construct validity was determined by examining the magnitude of the parameter coefficients. High parameter coefficients of greater than 0.5, indicate a close relation between the factor and an indicator variable. A parameter coefficient of 0.5 is interpreted as $25 \%$ of the total variance in the indicator variable being explained by the latent variable (factor). Therefore, a parameter coefficient has to be between 0.5 - 0.7 or greater to explain about $50 \%$ of the variance in an indicator variable (Hair et al., 1998). Inspection of the standardised parameter coefficient presented in Table 3, shown that they were significantly high (values ranged from 0.441 to 0.894 ). The estimate of 0.441 being the minimum suggested that the measured factor accounts for $46.87 \%$ of the variance in predicting the residents' satisfaction with their houses. The total variances accounted for in each indicator variables by the endogenous variable revealed that the scores were significance at $5 \%$ level.

Inspection of the interfactor correlation $\left(\mathrm{R}^{2}\right)$ values for the building quality feature indicators revealed that four out of the six indicator variables that were used to measure the latent factor, had values close to the desired value of 1.00. Two other variables (BQF3 \& BQF11) were weak in predicting the endogenous variable (Table 3). BQF3, which measured the occupants' level of satisfaction with the water pressure in their units, had the lowest $\mathrm{R}^{2}$ value. The interfactor correlation test statistics (Z-stats) which functions as a Z-statistics test that the estimate is statistically different from zero. Findings on this aspect revealed that the estimate is statistically different from zero. This suggests that the interfactor relationship of these variables and other indicators in determining overall residential satisfaction is minor. The reported parameter coefficient explained more than $25 \%$ of the variance in the latent variable, which were indicative of an adequate fit between the latent variables and the endogenous construct. Thus, the score results suggested that the influence of this latent factor on the endogenous variable was direct and significant. 


\section{Discussion \& Conclusion}

The finding was that building quality features indicator variables satisfied both internal reliability and the construct validity criteria. The Rho value was above the minimum value of 0.70 (Table 3) and the construct validity criteria was justified by the magnitude, and statistical significance of a majority of the parameter coefficients.

The findings from the interfactor relationship revealed that building quality features have a direct influence on the prediction of residents' housing satisfaction. From the assessment of the variance accounted for in each measure by the variable, it was also found that all scores were statistically significance at 5\% level. Likewise, the reported parameter coefficient explained more than the baseline level of the variance in the latent variable, were indicative of an adequate prediction of the residents' satisfaction with their houses. Hence, these results suggested that the influence of this latent factor on the endogenous variable was direct and statistically significant.

The six indicator variables used in measuring building quality features construct were highly causative to the endogenous variable as shown in Table 3 . The wall and floor quality were the most highly causative items followed by the plumbing quality indicator. The lowest causative items were the water pressure, the quality of finishing of the sanitary system and the internal construction quality. The findings suggest that the residents were satisfied with most of the building quality features, albeit, they were dissatisfied with the finish quality of the sanitary system and the internal construction quality of the units. These finding support the study done by Abdul Ghani (2008) who found that residents of low cost housing in Malaysia were partially satisfied with the building quality features. It also concurs with the findings of study done by Salleh et al. (2011) and Ukoha and Beamish (1997), which found that most respondents (low-income occupants) were dissatisfied with the qualities of the internal construction of their units. However, during the questionnaire survey, the researcher observed that most of the units had problems with the quality of their housing units. Complaints from the occupants varied from roofs and doors that were improperly built due to poor craftsmanship to doors that did not open or close properly. The lack of ceilings in most units also led to high levels of dissatisfaction because residents complained about extreme in temperature conditions during seasonal changes. According to Turner (1972), the value of a house is of greater importance to a person than the appearance of the housing unit. In addition, the structure of the house, even if the building material was of a lower standard, would not affect the person's perception if value could be attached to the unit. This is clearly evident from the results of this study.

Literature informs that good building structure with good quality is an important indicator that determines the residents' satisfaction with the building and the value they place on the dwelling (Kutty, 1999). Also, Duncan (1971) and Ramdane and Abdullah (2000), stated that the internal construction quality of a dwelling unit are usually considered with regards to its overall satisfaction, and when adequate, the occupants will be satisfied with their housing product. Findings revealed that the occupants were not totally satisfied as the measure of covariance and interfactor association with the residential satisfaction variable was average (Table 3).

The implication of these findings are that residents' satisfaction is a product of the direct influence of building quality features and that the residential satisfaction of South Africa lowincome housing occupants can be enhanced through improvement of the building quality features. The findings originating from the building quality feature assessment were therefore significant because when attention is given to issues of dissatisfaction regarding the building features various aspects, housing satisfaction of the low-income group residing in the subsidised houses will be achieved. Besides, the findings make it possible for policy makers 
to address factors of building quality in a way that it will bring about occupants' satisfaction with their houses.

\section{References}

Abdul Ghani, S. (2008). Neighbourhood factors in private low cost housing in Malaysia. Habitat International, Vol. 32, No. 4. (December 2008), pp. 485-493.

Aigbavboa, C.O. (2010). An evaluation of the post occupancy experience of housing subsidy beneficiaries in South Africa: A case study of Gauteng. Johannesburg: University of Johannesburg.

Aigbavboa, C.O. \& Thwala, W.D. (2012). An appraisal of housing satisfaction in South Africa low income housing scheme. The International Journal of Construction Management, 12(1), pp. 1-21.

Aigbavboa, C.O. \& Thwala, W.D. (2013). Confirmatory factor analysis of neighbourhood features amongst South Africa low-income housing occupants. In: Yaowu Wang et al. (Eds), Proc International Conference on Construction and Real Estate Management (ICCREM 2013), 11-12 October 2013, Karlsruhe, Germany.

Altas, N.E and Ozsoy, A. 1998. Spatial adaptability and flexibility as parameters of user satisfaction for quality housing. Building Environment, 33(5):315-323

Bentler, P.M. (1988). Causal modeling via structural equation systems in Handbook of multivariate experimental psychology, Perspectives on individual differences, eds. J.R. Nesselroade \& R.B. Cattell, Plenum Press, New York, NY, US, pp. 317-335.

Bentler, P.M. \& Wu, E.J. (2005). EQS 6.1 for windows. Encino, CA: Multivariate Software Inc. p. 1-26.

Bollen, K.A. (1989). Structural Equations with Latent Variables. New York: John Wiley \& Sons, Inc.

Byrne, B.M. (2006). Structural equation modelling with EQS- Basic concepts, Applications and programming. Lawrence Erlbaum Associates, Mahwah.

Duncan, T.L.C. (1971). Measuring housing quality: A study of methods. Centre for Urban and Regional Studies: University of Birmingham.

Elsinga, M. \& Hoekstra, J. (2005). Homeownership and housing satisfaction. Journal of Housing and the Built Environment, 20:401-424.

Francescato, G., Weidemann, S. \& Anderson, J.R. (1987). Residential satisfaction: its uses and limitations in housing research in Housing and neighbourhood: Theoretical and empirical contributions, W.V. Vliet, H. Choldin, W. Michelson \& P. Popene, Greenwood Press: Westport, CT, pp. 43-57.

Franescato, G., Weidemann, S., Anderson, J. R. and Chenoweth, R. (1974). Evaluating residents' satisfaction in housing for low and moderate income families: A multi-method approach. In: Carson DH, editor. Man-environment interactions: Evaluation and applications, vol. 5. Washington, D.C.: Environmental Design Research Association, p. 285-96.

Galster, G.C. \& Hesser, G.W. (1981). Residential satisfaction: An empirical critique. Environment and behavior, 13(6):735-758.

Gilbert, A. (2004). Helping the poor through housing subsidies: Lessons from Chile, Colombia and South Africa. Habitat international, 28(1):13-40.

Hayes, B.E. (1998). Measuring customer satisfaction: survey design, use and statistical analysis methods. Milwaukee: ASQ Quality Press.

Hourihan, K. (1984). Context-dependent models of residential satisfaction: An analysis of housing groups in cork Ireland. Environment and behavior, 16:369-393.

Hintz, M and Null, R.L. 1988. Satisfaction with structural quality of condominiums by owner-occupants. Housing and Society, 15(3), 227-237 
Huchzermeyer, M. (2001). Housing for the poor? Negotiated housing policy in South Africa. Habitat International, 25(3), 303-331.

Huchzermeyer, M. (2003). A legacy of control? The capital subsidy for housing, and informal settlement intervention in South Africa. International Journal of Urban and Regional Research, 27(3):591-612.

Huchzermeyer, M. and Karam, A. (2006). Informal settlements: a perpetual challenge? Juta Academic.

Kain, J.F. \& Quigley, J.M. (1970). Measuring the value of housing quality. Journal of the American statistical association, 65(330):532-48.

Kinsey, J. \& Lane, S. (1983). Race, housing attributes and satisfaction with housing. Housing and society, 1098-116.

Kline, R.B. (2005). Principles and practice of structural equation modeling. 2nd edn. New York: Guilford Press.

Kutty, N.K. (1999). Determinants of structural adequacy of dwellings. Journal of housing research, 10(1):1-27.

Landman, K. \& Napier, M. (2010). Waiting for a house or building your own? Reconsidering state provision, aided and unaided self-help in South Africa. Habitat international, 34(3):299-305.

Lu, M. (1999). Determinants of residential satisfaction: Ordered Logit vs. regression models. Growth and change, 30(Spring):264-287.

Marans, R. \& Sprecklemeyer, K. (1981). Evaluating Built Environment: A Behavioral Approach Michigan: The University of Michigan: Ann Arbor.

McCray, J.W. \& Day, S.S. (1977). Housing values, aspirations, and satisfactions as indicators of housing needs. Home economics research journal, 5:244-254.

Morris, E.W. \& Winter, M. (1978). Housing, Family and Society. John Wiley and Sons: New York.

Onibokun, A.G. (1974). Evaluating consumers' satisfaction with housing: An application of a system approach. Journal of American Institute of Planners, 40(3):189-200.

Potter, J., Chicoine, L. \& Speicher, E. (2001). Predicting Residential Satisfaction: A Comparative Case Study in EDRA 32 Proceedings University of Nebraska - Lincoln.

Ramdane, D. \& Abdullah, A.A. (2000). Satisfaction level with Neighborhood's in lowincome public housing in Yemen. Property management, 18(4):230-242.

Salleh, A., Yusof, N.A., Salleh, A.G. \& Johan Noraire, D. (2011). Tenant satisfaction in public housing and its relationships with rent arrears: Majlis Badaraya Ipoh, Oerak, Malaysia. International journal of trade economics and finance, 2(1):10-18.

Tomlinson, M. (1998). South Africas new housing policy: an assessment of the first two years, 1994 \{96. International Journal of Urban and Regional Research, 22(1):137-146.

Tomlinson, M. (1999). South Africa's housing policy. Lessons from four years of the new Housing Subsidy Scheme. Third World Planning Review, 21(3), 283-295.

Turner, J.F.C. (1972). Housing as a verb. Freedom to build, dwellers control of the housing process. eds. J.F.C. Turner \& R. Fibhter, New York: M Macmillan.

Turner, J. F. C. (1976) Housing by people: Towards autonomy in building environments. London, Marion Byers.

Ukoha, O.M. \& Beamish, J.O. (1997). Assessment of residents' satisfaction with public housing in Abuja, Nigeria. Habitat International, 21(4):445-460.

Varady, D.P. \& Carrozza, M.A. (2000). Towards a better way to measure customer satisfaction levels in public housing: A report from Cincinnati. Housing studies, 15(6)797825.

Weidemann, S. \& Anderson, J. (1982). Residents' perceptions of satisfaction and safety: A basis for change in multifamily housing. Environment and behavior, 14(6):695-724. 
Weidemann, S. \& Anderson, J.R.A. (1985). A conceptual framework for residential satisfaction. In Home environment. I. Atman \& R. Werner, Plenum Press, New York. Yiping, F. (2005). Residential satisfaction conceptual framework revisited- A study on redeveloped neighbourhood in inner-city Beijing. University of Colorado at Denver. An unpublished doctoral dissertation. 